\title{
Hand Wasting Due to Mid-Cervical Spinal Cord Compression
}

\author{
A.E. Goodridge, T.E. Feasby, G.C. Ebers, W.F. Brown and G.P.A. Rice
}

\begin{abstract}
Three patients presented with hand wasting and weakness secondary to mid-cervical spinal cord compression. This was due to cervical spondylosis in two patients and a meningioma in one case. This phenomenon is probably similar to that seen with foramen magnum lesions and may be due to spinal cord ischemia distal to the compression, secondary to venous stasis.
\end{abstract}

\begin{abstract}
RÉSUMÉ: Atrophie de la main due à une compression médullaire localisée à la région cervicale moyenne. Trois patients ont consulté pour de l'atrophie et de la faiblesse à la main secondaires à une compression médullaire à la région cervicale moyenne. Cette symptomatologie était due à une spondylose cervicale chez deux patients et à un méningiome dans l'autre cas. Ce phénomène est probablement semblable à celui que l'on rencontre dans les lésions du trou occipital et peut être causé par l'ischémie de la moelle épinière, secondaire à la stase veineuse, en aval de la compression.
\end{abstract}

Can. J. Neurol. Sci. 1987; 14:309-3II

Hand wasting has not been commonly reported with lesions of the middle cervical spinal cord' although it is a well known feature of compressive lesions at the foramen magnum. ${ }^{2-4} \mathrm{We}$ describe three patients with hand wasting due to mid-cervical cord lesions and discuss the significance of this clinical finding.

\section{Case Histories}

Patient 1: This 41-year-old woman presented with a sixteen month history of wasting and weakness of her left hand which she first noted after a minor hand injury. She had minimal pain of the left side of her neck and left upper arm. This was not characteristic of radicular pain. On physical examination, movement of the neck was normal. There was marked wasting and weakness of all the intrinsic muscles in the left hand. There was slight wasting and weakness of the left forearm flexors and extensors. The sensory exam and remainder of the neurological examination was normal. The electrophysiological studies on the left revealed a slight reduction of the fifth digit sensory nerve action potential and active denervation in both the abductor pollicus brevis and the first dorsal interosseus. The motor conduction studies were normal in the median and ulnar nerves. X-Rays of the cervical intervertebral foramina were normal. The transverse processes of $\mathrm{C} 7$ were prominent bilaterally. A cervical myelogram revealed a large anterior extradural defect at C5-6 (Figure 1). She had an anterior cervical discectomy and fusion at C5-6. Post-operatively she had complete resolution of her preoperative pain and subjectively found that the function of the left hand had improved although no change in strength was noted. Repeat EMG seven months later showed improvement with less denervation in the thenar muscles. At follow-up four years later there was no evidence of any improvement in strength.

Patient 2: This 44-year-old woman had an eight year history of pain extending from the right elbow to the wrist. For six years she had mild progressive weakness of the right hand and forearm muscles. There was no neck pain. Examination showed slight wasting and weakness of the right forearm flexors and extensors and marked wasting and weakness of all the intrinsic hand muscles on the right. There was no sensory deficit and the remainder of the neurological exam was normal. Electrophysiological studies on the right revealed clear evidence of motor unit loss in the intrinsic muscles of the hand, as well as extensor digitorum communis and flexor digitorium sublimis. The motor unit loss was most severe in the intrinsic hand muscles, thenar more than hypothenar. The motor units were large with occasional linked components. Motor conduction study of the ulnar nerve was normal but there was prolongation of the distal latency in the median nerve at the level of the carpal tunnel. The third digit - median and Sth digit - ulnar sensory nerve action potentials were normal. X-Rays of the cervical spine showed disc space narrowing at C4-5 and C5.6 with anterior osteophytes at both of these levels and slight impingement on the right C4-5 neural foramen. The lower cervical intervertebral foramina were normal. The myelogram showed compression of the spinal cord by anterior extradural defects at C4-5 and C5-6 and mild bilateral nerve root deformities at C5-6. A delayed CT Scan of the complete spine did not show evidence of syringomyelia. The patient did not have surgery although it was felt that the abnormalities seen at myelography explained the symptoms and signs.

Patient 3: This 56-year-old right-handed woman began to have gradually progressive weakness and numbness of her right hand in August 1985. 
In October, she tripped and fractured her right ankle and thereafter noted stiffness in the right leg. Slight numbness of the left leg was noted in January 1986. She experienced occasional mild neck pain. Examination in February 1986 revealed moderate wasting of the right first dorsal interosseous muscle, the thenar muscles and the extensor surface of the right forearm. There was slightly increased tone in the right pronator teres and quadriceps muscles. There was mild weakness of the right supraspinatus, deltoid, biceps and triceps muscles, moderate weakness of wrist flexion and extension and marked weakness of the intrinsic hand muscles. There was moderate weakness in the right leg and severe weakness of ankle dorsiflexion. Temperature and pain sensation were reduced on the right below T7. Vibration and position sensation were normal. The tendon reflexes were all present and brisk and those at the right knee and ankle were hyperactive. The right toe was upgoing.

Electrophysiological studies on the right showed active denervation in the first dorsal interosseous and abductor pollicus brevis muscles but not in the extensor digitorum communis, flexor digitorum communis or triceps. The third digit - median and fifth digit - ulnar sensory nerve action potentials were normal. The median motor study was normal although the ulnar motor study showed mild slowing across the cubital tunnel.

A myelogram (Figure 2) revealed a large round extradural mass on the right at C5. At surgery, a large meningioma was removed completely. At follow-up, ten weeks later, she was much improved. There was only mild weakness throughout her right arm and leg including her intrinsic hand muscles and ankle dorsiflexors. The hand wasting had diminished. The sensory exam was unchanged.

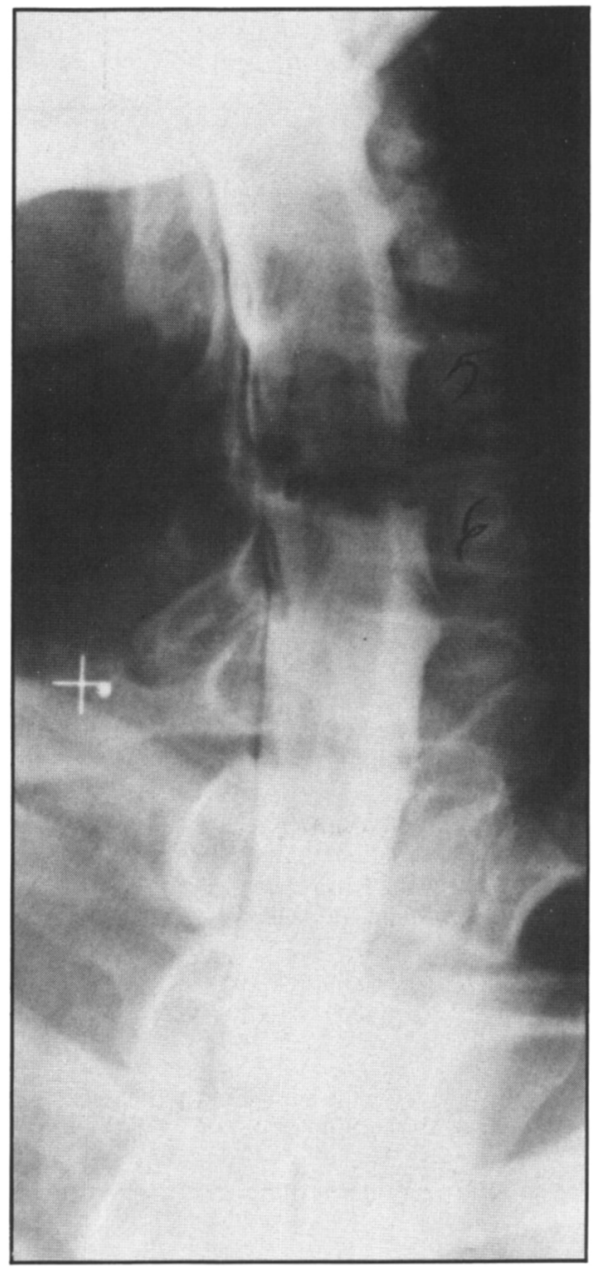

Figure I - Metrizamide myelogram of patient I showing exrradural compression of the cord due to a C5-6 disc protrusion.

\section{Discussion}

All the patients in this study had moderate to severe hand weakness and wasting. Although the major clinical involvement was at the $\mathrm{C} 8$ and $\mathrm{T} 1$ myotomes, the lowest level of cord compression was at $\mathrm{C} 5$ in one patient and at C5-6 in two patients. There was no evidence of other intramedullary or extramedullary lesions. The lower cervical intervertebral foramina were normal.

One patient had prolongation of the median nerve terminal latency and one patient had slight slowing of ulnar motor conduction at the elbow. However, in all patients, the distribution of the wasting was greater than could be explained on the basis of a single compressive lesion of either the median or ulnar nerves.

Patient I had some features of thoracic outlet syndrome, as outlined by Gillatt. ${ }^{5}$ These included the predominance of thenar wasting, the slightly reduced sensory nerve action potential in 5 th digit and the prominent transverse processes at C7. However, this patient had no pain or sensory symptoms along the medial forearm or in the fifth digit. This contrasts with those patients of Gilliatt, ${ }^{5}$ all of whom had a sensory disturbance, usually preceding the motor involvement. It was this atypical feature that lead to the search for an alternate explanation and discovery of the significant extradural defect.

In Patient 2, the fifth digit sensory nerve action potential was unequivocally normal. In Gilliatt's ${ }^{5.6}$ reports, all 22 patients described had absent, reduced or low normal sensory nerve

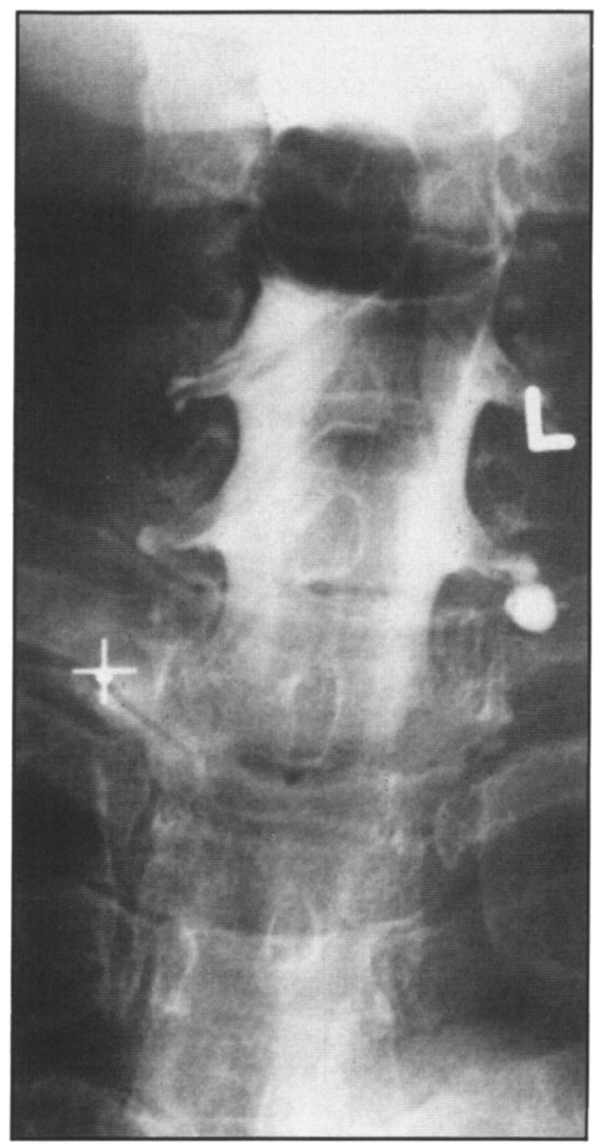

Figure 2 - Metrizamide myelogram of case 3 showing an extradural defect (meningioma) with cord compression at $\mathrm{C5}$. 
action potentials. We therefore felt the lesion in our patient had to be proximal to the dorsal root ganglia as the myelogram confirmed.

In Patient 3 the normal 5th digit sensory nerve action potential along with the associated myelopathy provide good evidence that all of the clinical findings were due to the radiologically demonstrated lesion. This was supported by the post operative improvement.

The differential diagnosis of hand wasting is extensive. Entrapment and other focal lesions of the median and ulnar nerves each produce a specific pattern of hand wasting. Brachial plexopathies, either idiopathic or as a result of a cervical rib or band, vasculitis, tumour infiltration or radiation may all cause hand wasting. Nerve roots may be compressed by a disc, spondylitic bar or tumour or may be infiltrated by malignant cells. A number of intramedullary and extramedullary lesions must also be considered, including syringomyelia and tumours. Amyotrophic lateral sclerosis may present with hand wasting, before more widespread features emerge.

The occurrence of hand wasting with cervical lesions at or near the foramen magnum has long been recognized. Wasting in the $\mathrm{C} 6, \mathrm{C} 7, \mathrm{C} 8$ and $\mathrm{Tl}$ distribution with upper cervical cord compression was first described by Oppenheim ${ }^{7}$ in 1913. Tay$\operatorname{lor}^{8}$ reviewed twelve of his own cases and forty-one in the literature of patients with compressive lesions at the foramen magnum or high in the cervical cord. Fifty percent of these patients had atrophy of the hand and forearm muscles. Yasuoka ${ }^{4}$ reviewed fifty-seven cases of benign extra medullary tumours at the foramen magnum. Excluding the ten patients with von Recklinghausen's disease, seventeen percent of his patients had hand wasting.

Hand wasting has not been commonly reported in cervical spondylosis. Brain ${ }^{9}$ in his review of cervical spondylosis, noted the occurrence of hand wasting with spondylitic cord compression as high as C3-4, but did not comment on its frequency. Bradshaw ${ }^{10}$ examined seventy-eight patients with cervical spondylosis. Intrinsic hand muscle wasting was found in seventeen patients although this was not correlated with the myelographic abnormalities. Stark' described two patients with spondylitic narrowing of the spinal cord at C3-4 and C5-6 respectively with upper extremity wasting most marked in the hands.

Spondylitic radiculopathy of the $\mathrm{C} 8$ nerve root is uncommon involving only ten percent of all cervical radiculopathies. ${ }^{10}$ Smith " pointed out that hand wasting in cervical spondylosis is more frequently due to myelopathy than radiculopathy. The frequency of hand wasting in cervical spondylitic myelopathy is not known but may be more common than thought because of failure to recognize this as a clinical entity.

The mechanism of hand wasting with mid or upper cervical cord lesions remains speculative. Mair ${ }^{12}$ examined the pathology of spinal cord lesions and their relationship to clinical features in the protrusion of cervical intervertebral discs. He had four cases, two of which had hand wasting. One of these patients had multiple protrusions from $\mathrm{C} 4$ to $\mathrm{T} 1$ most marked at C4-5 and the other had a C4-5 bulge. Both of these patients had loss of anterior horn cells extending to the first thoracic segment. He and others ${ }^{13,14}$ speculated that the likely mechanism was compression of the anterior spinal artery producing ischemia. The theory of obstruction of the anterior spinal artery, however, is difficult to accept. The pressures necessary to obstruct this artery must be in excess of $50 \mathrm{~mm}$ of mercury. The presence of large radicular branches joining the anterior spinal artery in the middle of the cervical enlargement would provide collateral blood supply. Furthermore, the clinical deficits are frequently unilateral despite the bilateral supply of the anterior spinal artery.

Taylor, ${ }^{8}$ in an excellent literature review and pathological study provided good evidence that the venous drainage of cervical cord grey matter is upward from $\mathrm{T} 1$ to $\mathrm{C} 2$, that the grey matter system is separate from the white matter system and that the two sides are to some extent separate from each other. The hygroscopic "tumours" he inserted in the high cervical region in Rhesus monkeys caused obstruction of the paracentral veins below this level with hypoxic changes and pericapillary haemorrhages in the anterior and posterior horns. These findings, which were maximal in the lower cervical region, suggested that the mechanism was due to venous stasis.

The distal portion of this upwardly draining venous system develops the changes first and these progress upwards as the process advances, thereby causing weakness and wasting in the lower cervical myotomes before the mid cervical myotomes. As the venous drainage system is bilaterally represented, unilateral clinical involvement can be explained on the basis of predominantly unilateral compression.

Compressive lesions of the mid cervical spinal cord, especially with cervical spondylosis should be considered in the differential diagnosis of hand wasting. Cases suspected clinically to have thoracic outlet syndrome, but without typical sensory symptoms or electrophysiological abnormalities, may require myelography to exclude a compressive cord lesion. The mechanism of anterior horn cell loss several segments below a compressive lesion is unknown but may be due to cord ischemia caused by venous obstruction.

\section{REFERENCES}

1. Stark RJ, Kennard C, Swash M. Hand wasting in spondylitic high cord compression: An electromyographic study. Ann Neurol 1981; 9: 58-62.

2. Stein BM, Leeds NE, Taveras JM, Pool JL. Meningiomas of the foramen magnum. J Neurosurg 1948; 20: 740-751.

3. Cohen L, McRae D. Tumours in the region of the foramen magnum. J Neurosurg 1962; 19: 462-469.

4. Yasuoka S, Okazaki H, Daube JR et al. Foramen magnum tumours: Analysis of 57 cases of benign intramedullary tumours. J Neurosurg 1978; 49: 828-838.

5. Gilliatt RW, LeQuesne PM, Logue V et al. Wasting of the hand associated with a cervical rib or band. J Neurol Neurosurg Psychiat 1970; 33: 615-624.

6. Gilliatt RW, Willison RG, Dietz V et al. Peripheral nerve conduction in patients with a cervical rib or band. Ann Neurol 1978; 4: 124-129.

7. Oppenheim $\mathrm{H}$. Weitere Beitrage zuv diagnose und differentialdiagnose des tumour medullae spinalis. Mschr Psychiatr Neurol 1913: 33: 451-493.

8. Taylor AR, Byrnes DP. Foramen magnum and high cervical cord compression. Brain 1974; 97: 473-480.

9. Brain WR, Northfield D, Wilkinson M. The neurological manifestations of cervical spondylosis. Brain 1952; 75: 187-225.

10. Bradshaw P. Some aspects of cervical spondylosis. Quarterly J Medicine 1957; 26: 177-207.

11. Smith BH. Cervical spondylosis and its neurological complications. Springfield, Charles C. Thomas. 1968.

12. Mair WPG, Druckman R. The pathology of spinal cord lesions and their relation to the clinical features in protrusion of cervical intervertebral discs (A report of four cases). Brain 1953; 76: 70-91.

13. Taylor AR, Aberd MD. Vascular factors in the myelopathy associated with cervical spondylosis. Neurology 1964; 14: 62-68.

14. Hughes JT, Brownell B. Cervical spondylosis complicated by anterior spinal artery thrombosis. Neurology 1964; 14: 1073-1077. 